\title{
Regulation of phosphatidylserine exposure and phagocytosis of apoptotic T lymphocytes
}

\author{
Bret Verhoven ${ }^{1}$, Stephen Krahling ${ }^{2}$, Robert A. Schlegel ${ }^{2}$ and \\ Patrick Williamson*,1 \\ ${ }^{1}$ Department of Biology, Amherst College, Amherst, Massachusetts 01002, USA \\ 2 Department of Biochemistry and Molecular Biology, Penn State University, \\ University Park, Pennsylvania 16802, USA \\ * corresponding author: P. Williamson, Department of Biology, Amherst \\ College, Amherst, Massachusetts 01002, USA
}

Received 14.4.98; revised 20.11.98; accepted 10.12.98 Edited by B.A. Osborne

\begin{abstract}
In lymphocytes, an asymmetric distribution of phospholipids across the plasma membrane is maintained by an ATPdependent translocase which specifically transports aminophospholipids from the outer to the inner leaflet of the bilayer. During apoptosis, this enzyme is down-regulated and a lipid flipsite, termed the scramblase, is activated. Together, these events lead to the appearance of phosphatidylserine (PS) on the cell surface. In D011.10 T lymphocyte hybridoma cells undergoing apoptosis, the kinetics of PS externalization are paralleled by the development of PS-sensitive phagocytosis by macrophages. This parallel is also observed when PS externalization is effected directly by application of a $\mathrm{Ca}^{2+}$ ionophore, suggesting that PS externalization is not only necessary, but sufficient, to generate a recognition signal. The broad spectrum aspartate-directed cysteine protease (caspase) inhibitor ZVAD-fmk blocks externalization of PS and terminal cell lysis after induction of apoptosis by anti-CD3 antibody, but is ineffective when apoptosis is induced in the same cells by treatment with glucocorticoid. These results suggest that apoptosis induced by glucocorticoid does not require the same ZVAD-sensitive caspase steps which are required for Fas/FasL-dependent death induced by anti-CD3 antibody, and that the action of these proteases is also not required for PS externalization. Extracellular $\mathrm{Ca}^{2+}$ is required to complete the later stages of apoptosis in D011.10 cells, and its removal restores normal transport of PS, suggesting that down-regulation of the aminophospholipid translocase and up-regulation of the scramblase are not effected by irreversible protease cleavage.
\end{abstract}

Keywords: apoptosis; T lymphocytes; phagocytosis; cell surface molecules

Abbreviations: PS, phosphatidylserine; PC, phosphatidylcholine; zVAD-fmk, carbobenzoxy-valyl-alanyl-aspartyl-fluoromethylketone; CD3, cluster of differentiation 3; ICE, interleukin-1 $\beta$ converting enzyme; PARP, poly (ADP-ribose) polymerase; NBD, 12-[(7-nitro-2-1,3-benzoxadiazol-4-yl) amino] dodecanoyl; FITC, fluorescein isothiocyanate

\section{Introduction}

Presentation of signals triggering recognition and engulfment of apoptotic cells is a fundamental feature of most forms of programmed cell death. ${ }^{1}$ In a variety of cell types and regardless of the initiating stimulus, expression of phosphatidylserine (PS) on the cell surface is necessary for entombment of the dying cell. ${ }^{2-8}$ Normally, PS is not present in the external leaflet of the plasma membrane, reflecting the asymmetric distribution of phospholipids between the two leaflets of the bilayer. ${ }^{9}$ This lipid asymmetry is maintained by a P-type ATPase, ${ }^{10}$ called the aminophospholipid translocase, which transports the anionic phospholipids PS and phosphatidylethanolamine from the outer to the inner leaflet of the bilayer. ${ }^{11,12}$ However, the resulting asymmetric distribution can be randomized by activation of a second membrane protein, termed the scramblase, that catalyzes rapid, bidirectional transbilayer movement of all classes of phospholipids across the membrane. ${ }^{13-16}$ Coordinated inhibition of the translocase and activation of the scramblase occur in $\mathrm{T}$ lymphocytes undergoing apoptosis. ${ }^{17,18}$ These alterations in activity bring PS to the cell surface, prior to the characteristic DNA degradation, membrane blebbing and cell lysis that constitute later steps in the cell death pathway. ${ }^{17}$

A variety of stimuli induce apoptosis, acting through several different signaling pathways which eventually converge to a sequence of execution steps, the machinery for which is constitutively expressed and common to all cells. ${ }^{19}$ A growing family of aspartatedirected cysteine proteases (caspases) with homology to interleukin-1 $\beta$-converting enzyme (ICE) has been implicated in apoptosis. ${ }^{20}$ One of these caspases, encoded by the ced-3 gene, is required for apoptosis in the nematode C. elegans. $^{21}$ In vertebrates, ced-3/ICE-like proteases have been implicated in apoptosis induced by Fas ligand, ${ }^{22-24}$ growth factor deprivation ${ }^{25}$ and some forms of motor neuron death in vivo. ${ }^{26}$ The ced-3/ICE-like caspases in mammals are a complex family, with at least ten distinct members in humans. ${ }^{27}$ Of these, caspase-3 and -7 have the greatest sequence homology with ced-3, a high degree of substrate specificity, and rapid cleavage kinetics. ${ }^{28-30}$ Specific caspase inhibitors such as the viral CrmA protein ${ }^{25,28,31,32}$ and peptides that irreversibly bind to the protease active-site cysteine ${ }^{22-25,30,33}$ can block apoptosis, suggesting a role for these enzymes in the signaling phase of apoptosis, prior to the decision to enter the common execution phase. At the same time, the identification of caspase targets such as the nuclear enzyme poly (ADP-ribose) polymerase (PARP) ${ }^{22,28}$ indi- 
cate that these proteases may be actors in the execution phase of apoptosis as well.

In vivo, the process of apoptosis functionally culminates in the phagocytosis of dying cells, with later stages such as degradation of nuclear DNA only occurring in cells sequestered in phagocytic vacuoles. ${ }^{34-36}$ The redistribution of PS early in the apoptotic process ${ }^{4,17}$ and its requirement for phagocytosis ${ }^{2,6}$ raises the question of whether the appearance of PS on the cell surface is sufficient, as well as necessary, to signal recognition. Here, we confirm the relationship between exposure of PS and the susceptibility of cells to phagocytosis, and present evidence that in DO11.10 T lymphocyte hybridoma cells the former process is sufficient to trigger the latter. That PS becomes exposed early in the apoptotic process raises the question of whether caspases are involved in the mechanisms regulating PS distribution, and if so, whether they act during the triggering phase leading to the decision to enter the common death pathway, or as effectors in the execution steps following this decision. Using the broad spectrum caspase inhibitor zVAD-fmk, we show that activation of caspases is required for apoptosis in DO11.10 cells when the inducing stimulus is occupancy of the $\mathrm{T}$ cell receptor, but not when apoptosis is induced by glucocorticoid. Redistribution of PS is similarly sensitive to zVAD in cells induced by anti-CD3, indicating that this step is downstream of these caspase-dependent events, but is insensitive in cells induced by glucocorticoid, suggesting that PS exposure does not itself depend on activation of caspases and that the translocase and scramblase are not substrates of these proteases. We also show that alterations in translocase and scramblase activity are reversed by removal of extracellular $\mathrm{Ca}^{2+}$, suggesting that regulation of these proteins does not occur by direct cleavage by caspases, or by other proteolytic activities.

\section{Results}

PS is not normally present in the outer leaflet of the plasma membrane of DO11.10 T lymphocyte hybridoma cells, as evidenced by their failure to bind the PS-specific probe annexin $\mathrm{V}$ (Figure 1, upper inset). However, $4 \mathrm{~h}$ after treatment with anti-CD3 antibody to induce apoptosis, a population of DO11.10 cells appears which binds fluoresceinated annexin V, indicating surface exposure of PS (Figure 1, lower inset). These cells retain their membrane integrity, since they are not labeled by the impermeant DNA fluorophore YOPRO-3 iodide; they also retain the forward and side light scatter characteristics of ininduced cells, indicating that PS reaches the surface prior to the cell shrinkage and zeiosis stages of the apoptotic program (data not shown). The number of these cells in the population soon reaches a peak, then falls by about $8 \mathrm{~h}$ of induction as the responsive cells shrink, fragment, and lyse (see Figure 7, below). The appearance of cells displaying PS on their surface parallels precisely the appearance of cells with inactivated aminophospholipid translocase, the enzyme responsible for clearing PS from the cell surface, and activated scramblase, which randomizes phospholipids between the inner and outer leaflets of the bilayer ${ }^{17}$ (see Figure 5, below).

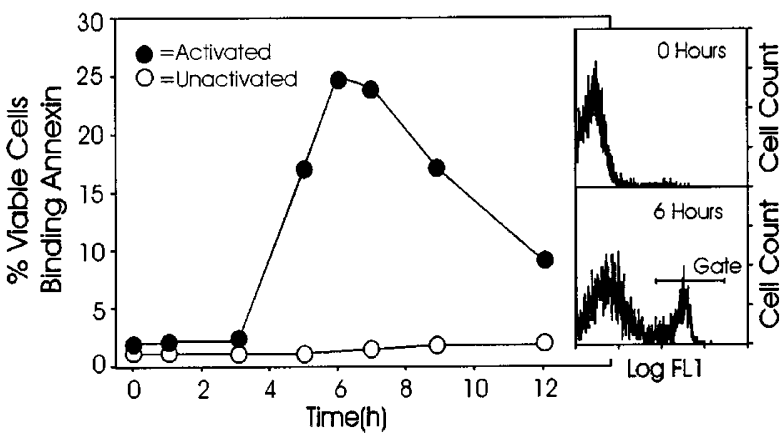

Figure 1 Annexin $\mathrm{V}$ binding to apoptotic D011.10 cells. YO-PRO-PInegative D011.10 cells, either stimulated with anti-CD3 antibody or left unstimulated as controls, were stained with annexin V-FITC and 5000 cells analyzed by flow cytometry. Cells within the indicated gate were considered positive for staining with annexin

Exposure of PS on the surface of apoptotic cells is required for phagocytosis by macrophages. ${ }^{2,6}$ The appearance of a functional phagocytosis signal on DO11.10 cells treated with anti-CD3 was measured as their rate of uptake by macrophages as a function of time after addition of antibody (Figure 2A). A small increase in the rate of phagocytosis was measurable after about $1 \mathrm{~h}$ of treatment (Figure 2A). This low level of interaction does not involve $\mathrm{PS}$, since it is insensitive to the addition of PS vesicles; it is also relatively invariant over time after its first appearance, and is observed well before intermediate apoptotic signaling events, such as the synthesis of Fas and FasL, are completed. ${ }^{37}$ This low level of recognition is then supplanted by a much larger increase in the rate of apoptotic cell phagocytosis. The new recognition process is blocked by PS vesicles and is low until about $4 \mathrm{~h}$ after induction of apoptosis, at which time it begins to rise dramatically. The increase in the rate of PS-sensivite uptake (Figure 2B) correlates well with the time course of PS appearance and the modulation of transbilayer lipid movements which underlie it. ${ }^{17}$

The correlation between PS appearance and the development of a functional phagocytosis signal suggests that the appearance of PS may not only be necessary, but also sufficient, to trigger recognition. However, recognition of apoptotic cells involves several cell surface molecules ${ }^{6}$ and the extended time between anti-CD3 administration and the exposure of PS $(4 \mathrm{~h})$ leaves open the possibility that some of these other surface components are not normally exposed and must be inserted into the membrane prior to PS exposure. To determine whether this is the case, cytosolic $\mathrm{Ca}^{2+}$ levels were elevated using extracellular $\mathrm{Ca}^{2+}$ and high levels of the $\mathrm{Ca}^{2+}$ ionophore, A23187. In other cell types, this treatment brings PS immediately to the cell surface by inhibiting the aminophospholipid translocase and activating the phospholipid scramblase. ${ }^{13,15,16}$ As shown in Figure 3, similar $\mathrm{Ca}^{2+}$. induced changes in lipid movements can be induced in D011.10 cells. Immediately upon treatment with $\mathrm{Ca}^{2+}$ and ionophore, the rate of transport of a fluorescent PS analog (NBD-PS) from the surface of the cell into the cell interior is 
dramatically reduced in $95 \%$ of the cells, indicating that the aminophospholipid translocase which mediates this transport is blocked (Figure 3A). At the same time, transbilayer movement of NBD-PC to the cell interior, which is diagnostic of the nonspecific scramblase, is activated in all cells, as indicated in Figure 3B. As would be expected, this combination of events results in the immediate appearance of PS on the cell surface, as judged by annexin binding (Figure $3 \mathrm{C}$ ).

This immediate ( $<5 \mathrm{~min}$ ) exposure of PS on the cell surface limits the time available for the development of components of the recognition signal other than PS itself. To determine whether a functional phagocytosis signal appeared under these circumstances, ionophore-treated cells were presented to macrophages. As shown in Figure $3 \mathrm{D}$, these cells were recognized by macrophages as quickly as uptake could be measured (the $30 \mathrm{~min}$ incubation required for the phagocytosis assay itself).
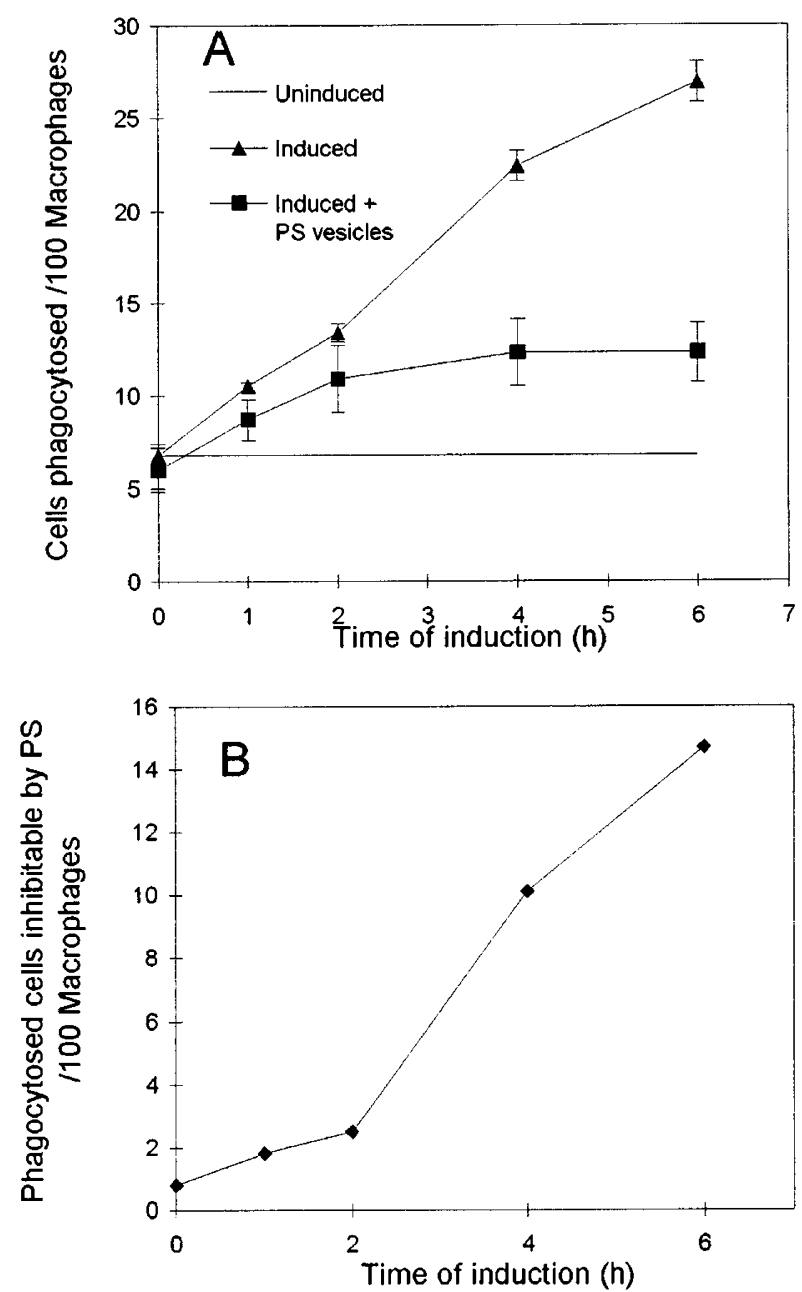

Figure 2 Phagocytosis of apoptotic D011.10 cells by elicited mouse peritoneal macrophages. D011.10 cells were incubated in the presence or absence of anti-CD3 antibody. At various times samples were taken, presented to peritoneal macrophages in the presence or absence of PS vesicles, and the number of lymphocytes phagocytosed in $30 \mathrm{~min}$ was counted. Values in $(\mathbf{B})$ are the difference between the values in $(\mathbf{A})$ for induced lymphocytes phagocytosed in the presence and absence of PS vesicles
Recognition was sensitive to inhibition by PS vesicles, and the level of recognition was complete at the earliest time, with no changes over several hours of incubation
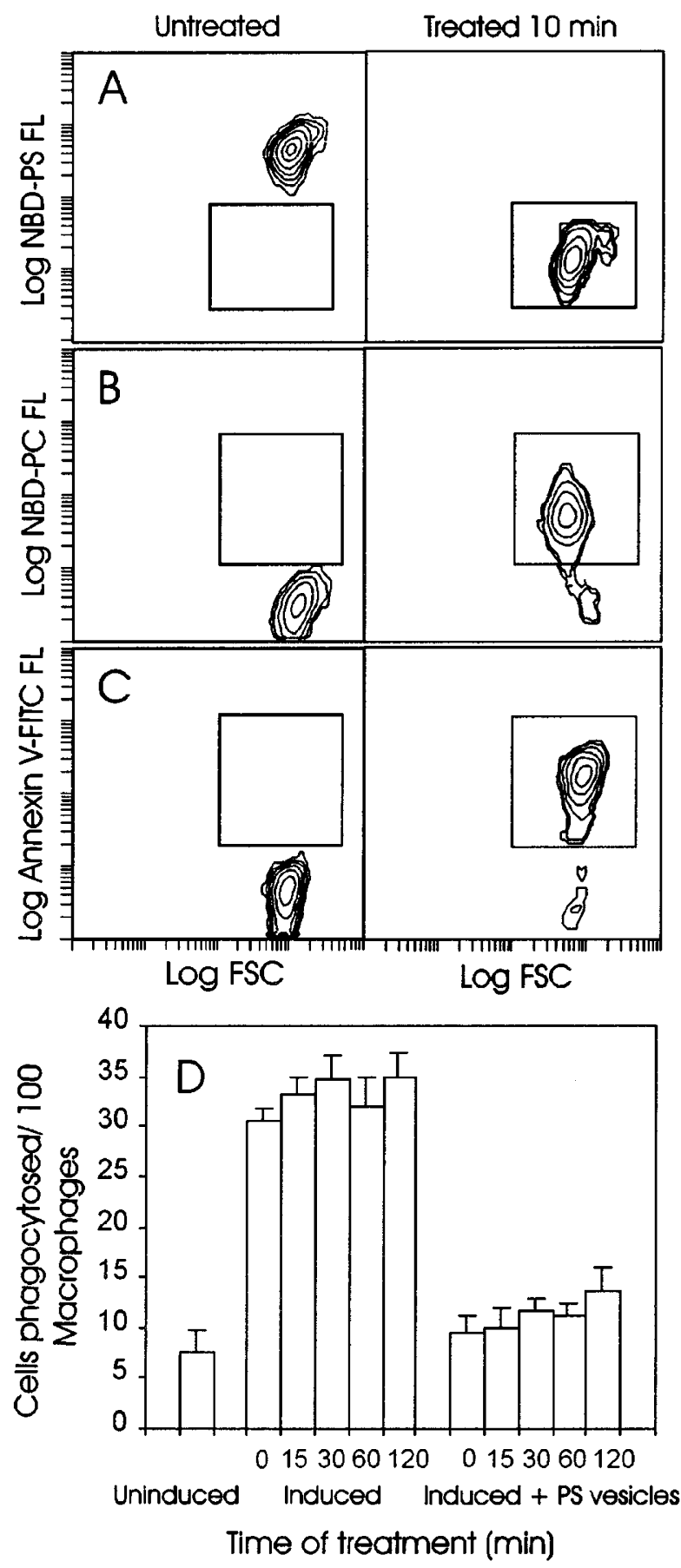

Figure 3 Alteration of translocase and scramblase activity in, and phagocytosis of DO11.10 cells treated with $\mathrm{Ca}^{2+}$ and the $\mathrm{Ca}^{2+}$ ionophore A23187. NBD-PS uptake (translocase activity), NBD-PC uptake (scramblase activity) and annexin $\mathrm{V}$ binding was analyzed in untreated cells and cells treated for $10 \mathrm{~min}$ with $10 \mu \mathrm{g} / \mathrm{ml} \mathrm{A23187} \mathrm{(A,} \mathrm{B} \mathrm{and} \mathrm{C).} \mathrm{At} \mathrm{various} \mathrm{times} \mathrm{after}$ $\mathrm{Ca}^{2+}$ and $\mathrm{A} 23187$ treatment cell samples were presented to peritoneal macrophages in the presence or absence of PS vesicles, and the number of lymphocytes phagocytosed in $30 \mathrm{~min}$ was counted (D) 
thereafter. Together, these results suggest that the exposure of PS during apoptosis is not only necessary, but sufficient to trigger phagocytosis, and that any other required components of the signal are already present on the cell surface when PS rearrangement takes place.

The generality and functional importance of PS exposure in the apoptotic program raises the issue of the signaling pathway that leads to the changes in lipid movements. One potentially important event is the activation of caspases, which have been shown to be essential for the progress of Fas/FasL-induced apoptosis in lymphoid cells. ${ }^{22-24}$ To investigate the role of these enzymes in D011.10 cells,
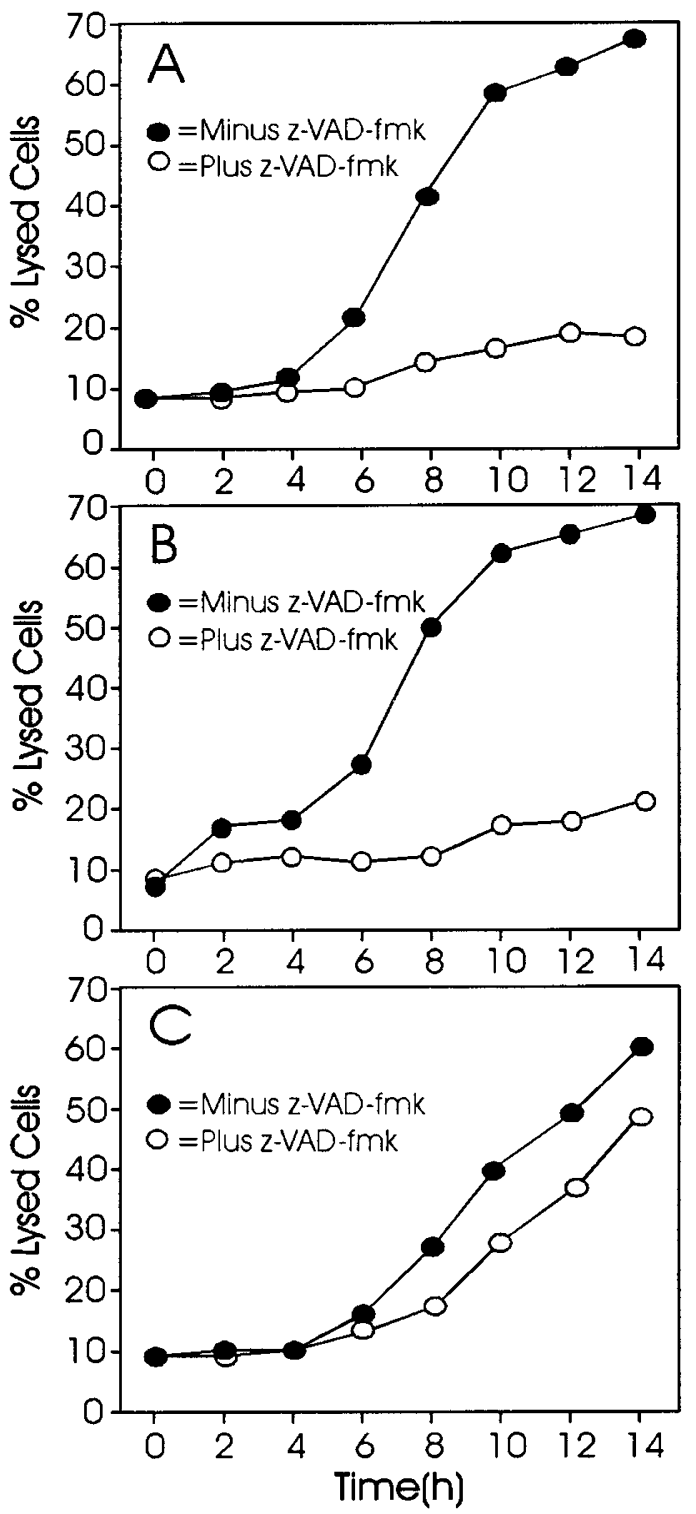

Figure 4 Effects of zVAD-fmk on lysis of apoptotic D011.10 cells. D011.10 cells were incubated in either medium alone or medium containing $10 \mu \mathrm{M}$ zVAD-fmk; apoptosis was induced by anti-CD3 antibody (A), PMA and ionophore (B) or dexamethasone (C). Lysis was monitored by flow cytometry by the inability of cells to exclude the membrane impermeable dye YO-PRO-PI at the specified times after induction the effects of the cell permeant, wide-spectrum caspase inhibitor zVAD-fmk on apoptosis were examined, using several different agents to induce apoptosis. To monitor the overall progress of apoptosis, cell lysis, which occurs in vitro in the absence of engulfment, was measured. As shown in Figure 4A, anti-CD3 induces progressive cell lysis, culminating at about $8 \mathrm{~h}$. This progression requires the action of zVAD-sensitive caspases since addition of inhibitor prevents cell lysis over the same time course (Figure 4A). Apoptosis can also be induced in DO11.10 cells by treatment with PMA and low levels of A23187 in the presence of extracellular $\mathrm{Ca}^{2+}{ }^{38}$ As shown in Figure 4B, the kinetics of apoptotic cell lysis after this treatment are similar to those seen using antiCD3, and death is similarly sensitive to zVAD-fmk. As shown in Figure 4C, apoptosis is also induced in DO11.10 cells by exposure to glucocorticoid. In this case, the final stages of cell lysis occur a little more slowly and less synchronously than in the case of anti-CD3- or PMA/ionophore-induced death. More importantly, cell death in this case is not blocked by zVAD-fmk (Figure 4C). Lack of an effect cannot be due to the inability of the cells to take up the inhibitor, or to the absence of a target, since zVAD-fmk effectively blocks the effects of the other two inducers of apoptosis in the same cells.

These experiments indicate that $z V A D$-sensitive caspase activity is required to complete anti-CD3- and PMA/ ionophore-induced, but not glucocorticoid-induced death. Apoptosis induced by all three agents includes translocase inhibition and scramblase activation as early events ${ }^{17}$ (and see Figure 6 below). To determine whether the caspase requirement for lysis, a late event in apoptosis, extends to these early events as well, the effect of zVAD-fmk on the alterations in lipid movement were examined. Aminopho-

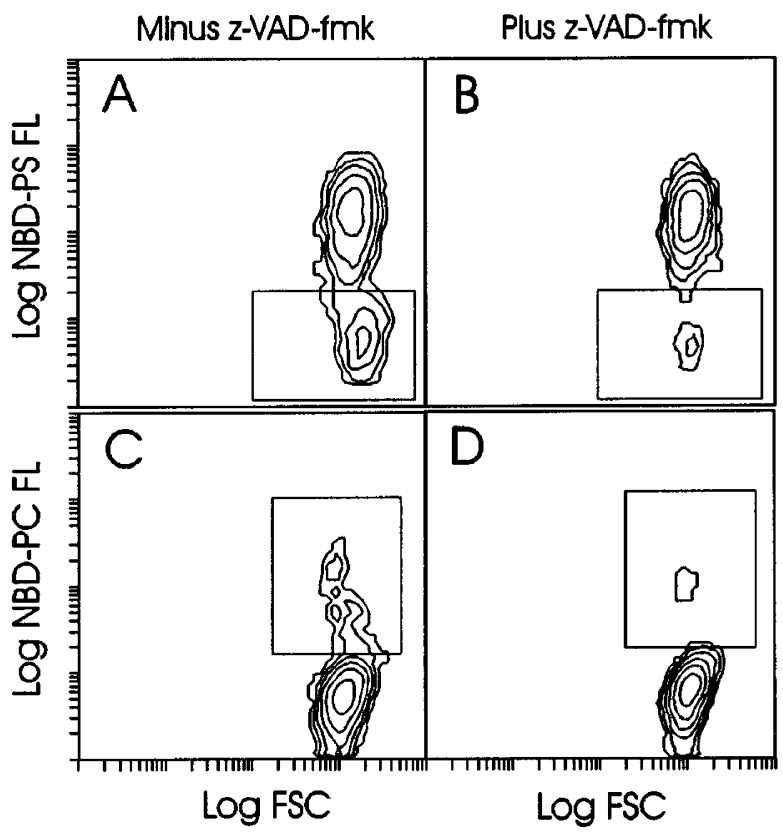

Figure 5 Effects of zVAD-fmk on lipid movements in apoptotic D011.10 cells induced by anti-CD3. Uptake of NBD-PS (translocase activity) or NBD-PC (scramblase activity) was monitored $6 \mathrm{~h}$ after induction in the absence (A and C) or presence (B and D) of $10 \mu \mathrm{M} z V A D-f m k$ 
spholipid translocase activity was determined by measuring the level of internalization of NBD-PS; the results for induction by anti-CD3 are shown in Figure 5 . In the absence of inhibitor, intact cells of normal size in which translocase is inactivated appear as a discrete population with reduced NBD-PS internalization (Figure $5 \mathrm{~A}$ ). The appearance of this population is blocked in the presence of zVAD-fmk (Figure 5B). Similarly, the appearance of cells in which NBD-PC is translocated to the cell interior by the activated scramblase (Figure $5 \mathrm{C}$ ) is also blocked by zVADfmk (Figure 5D).

These results imply that the z-VAD-sensitive step occurs at or upstream of PS redistribution during anti-CD3-induced apoptosis, and raise the question of whether caspases are also required for PS redistribution in glucocorticoid-treated cells, where cell lysis proceeds in the presence of inhibitor. As shown in Figure 6, the translocase is inactivated (Figure $6 \mathrm{~A}$ ) and the scramblase activated (Figure 6C) in glucocorticoid-induced cells just as in anti-CD3-induced

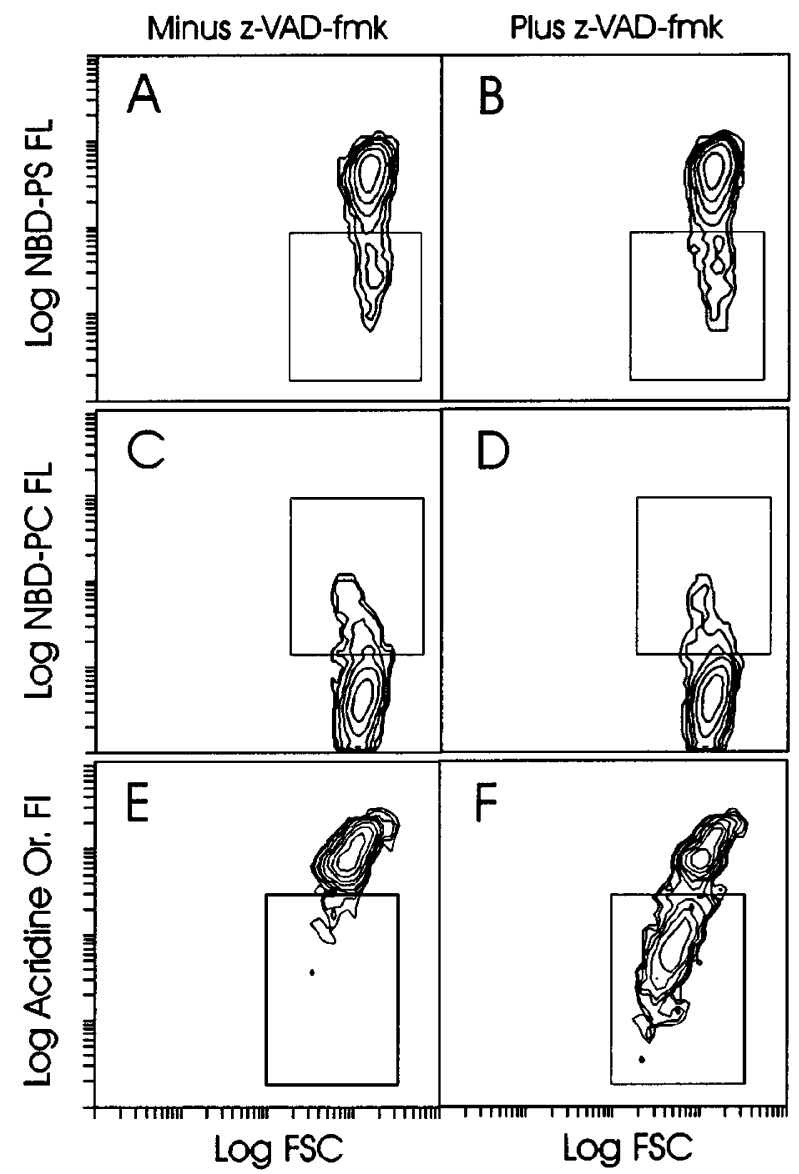

Figure 6 Effects of zVAD-fmk on lipid movements and DNA degradation in apoptotic D011.10 cells induced by dexamethasone. Uptake of NBD-PS (translocase activity) or NBD-PC (scramblase activity) was monitored $7 \mathrm{~h}$ after induction in the absence ( $\mathbf{A}$ and $\mathbf{C}$ ) or presence (B and $\mathbf{D})$ of $10 \mu \mathrm{M}$ zVAD-fmk. Chromatin degradation was monitored at the same time by flow cytometry of acridine orange stained, uninduced control cells $(\mathbf{E})$ and dexamethasoneinduced, zVAD-fmk treated cells (F) cells. However, in glucorticoid-induced cells both NBD-PS and NBD-PC movement occur normally in the presence of zVAD-fmk (Figure 6B and D) and annexin labeling confirms the externalization of endogenous PS (data not shown). Verification that cell death occurring in the presence of zVAD-fmk is apoptosis was obtained by staining with acridine orange and analyzing DNA degradation. As shown in Figure 6F, glucocorticoid-induced and zVAD-fmk treated cells with degraded chromatin are identified as a discrete subpopulation with reduced fluorescence compared to the normal population of cells in $G_{1} / G_{0}$ of the cell cycle (Figure 6E). These results indicate that caspase activity is not required for PS exposure in apoptosis induced by dexamethasone, and suggest that the translocation and scramblase are not direct targets of proteases inhibitable by zVAD-fmk.

Extracellular $\mathrm{Ca}^{2+}$ has been shown necessary for PS exposure on several other types of apoptotic cells. ${ }^{39}$ Similarly, addition of EGTA to DO11.10 cells at any time following induction with anti-CD3 prevents subsequent redistribution of $P S$ as well as further cell shrinkage and lysis (Figure $7 C$ and $D$ ) compared to untreated cells (Figure $7 \mathrm{~A}$ and $\mathrm{B}$ ). When EGTA was added at $6 \mathrm{~h}$ after induction

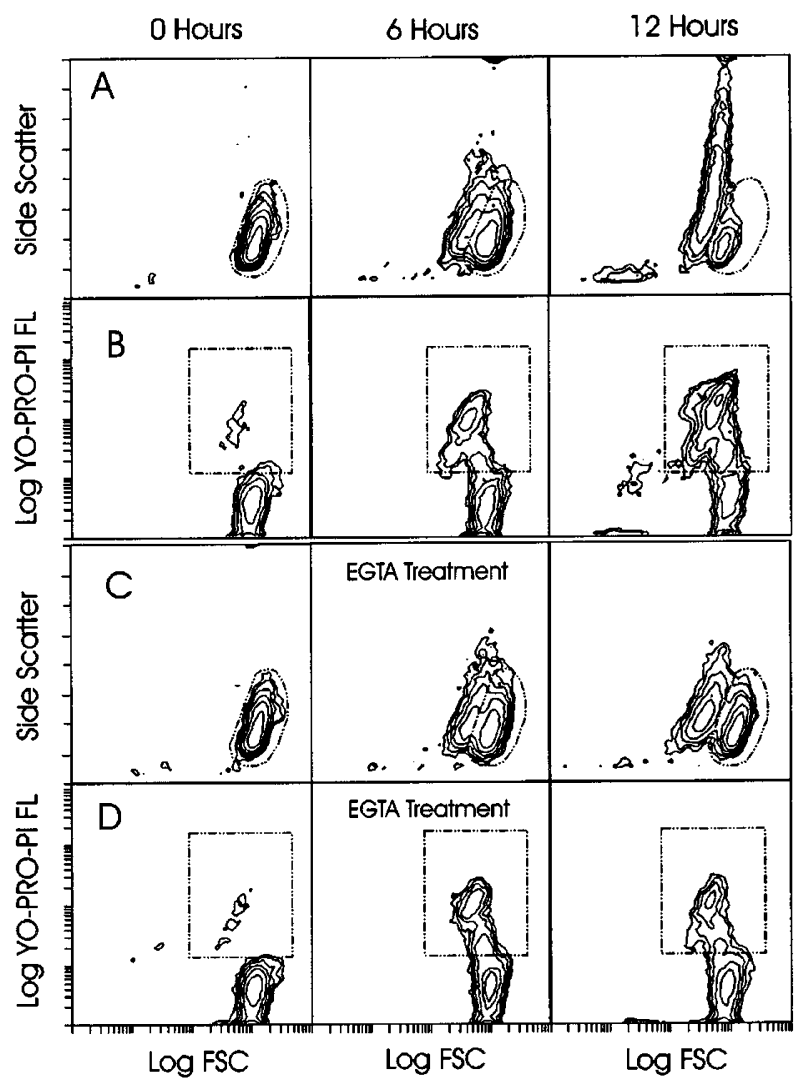

Figure 7 Effects of EGTA on cell shrinkage and lysis of D011.10 cells induced by anti-CD3. Shown is flow cytometric analysis of anti-CD3-induced control cells ( $\mathbf{A}$ and $\mathbf{B}$ ) and induced cells treated at $6 \mathrm{~h}$ with $2 \mathrm{mM} \mathrm{EGTA} \mathrm{(} \mathbf{C}$ and D). Cell size and density was monitored at various times via forward and side scatter (A and $\mathbf{C}$ ) while loss of membrane integrity was determined using YOPRO-PI (B and D) 


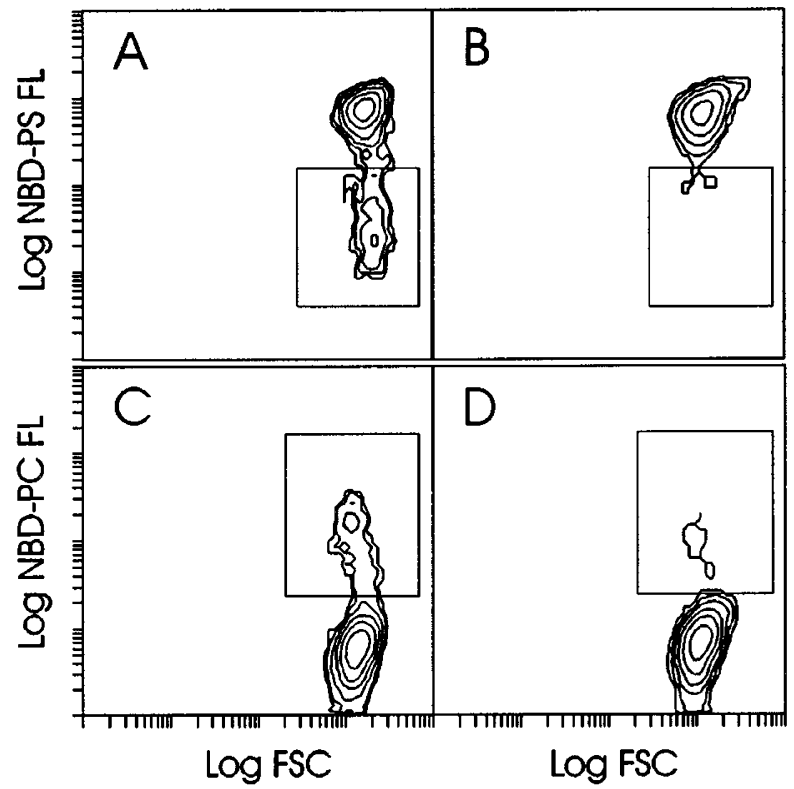

Figure 8 Effect of removal of extracellular $\mathrm{Ca}^{2+}$ on lipid movements in apoptotic D011.10 cells. Uptake of NBD-PS (translocase activity) or NBD-PC (scramblase activity) was monitored $6 \mathrm{~h}$ after stimulation with anti-CD3 in untreated control cells (A and $\mathbf{C}$ ) or cells treated for $15 \mathrm{~min}$ with $2 \mathrm{mM}$ EGTA (B and D)

with anti-CD3, at a time when cells with inactive translocase and active scramblase were present in the population (Figure $8 \mathrm{~A}$ and $\mathrm{C}$ ), these cells returned to their normal pattern of transporting NBD-PS but not NBD-PC (Figure 8B and $D$ ) lost the ability to bind annexin $V$ (data not shown). Similar results were obtained after induction with dexamethasone (data not shown). These results imply that PS exposure requires external $\mathrm{Ca}^{2+}$ in both activation- and glucocorticoid-induced apoptosis in DO11.10 cells. Moreover, the alteration in activity of both the translocase and scramblase is reversible, implying that neither of these enzymes is a direct target for proteases activated during apoptosis in DO11.10 cells.

\section{Discussion}

Cells differentiate to many different cell types in order to carry out differing specific functions required at various stages in the life of the organism. However, these various cell types all retain a capacity to continue differentiation in response to a variety of stimuli via a common program leading to cell death. Given the range of circumstances under which this common pathway is invoked, it is not surprising that there are many different signaling pathways through which cells enter it. Eventually, however, these signaling pathways necessarily converge, given that the final morphological features and molecular consequences of the execution phase are common to all cells. Distinguishing whether an event is part of an idiosyncratic upstream signaling pathway or part of the common execution phase requires distinguishing the two phases from each other. One way to distinguish the two phases is in a single cell system inducible by several stimuli.

Some properties of the final common pathway are clear. It does not require gene transcription or mRNA translation, for example, and the necessary molecular machinery is ubiquitously distributed in all cell types. ${ }^{19}$ Proteolytic degradation of selected cellular constituents is a common theme,${ }^{40}$ leading to destruction of cytoskeletal architecture, inactivation of the DNA repair machinery, and disassembly of an ordered chromatin array, among other events. In vivo, some of these degradative steps are likely to be functionally continuous with the processes leading to the ultimate measure of cell death, cell removal. In C. elegans, for example, a nuclease is required for removal of the apoptotic body. ${ }^{41}$ The gene for this nuclease must be expressed in an engulfing cell, while in mammals, activation of nucleases occurs in the apoptotic cell itself. Activation of these nucleases in the apoptotic or phagocytic cell is probably functionally equivalent, because in both cases digestion of the apoptotic cell DNA occurs after the dying cell has been recognized as such and phagocytosed by a living cell. ${ }^{35,36}$ In this sense, expression of signals for recognition by phagocytes is the death knell of apoptosis.

Degradation of the apoptotic cell occurs in a phagocytic vacuole because recognition of apoptotic cells is an early event in the common pathway. The machinery for recognition of apoptotic cells is complex. In the recognition of apoptotic blood cells by macrophages, integrin ${ }^{42}$ and lectin-like ${ }^{43}$ components, CD14 recognized by the antibody $61 \mathrm{D} 3,{ }^{44,45}$ and accessory components such as CD36 and thrombospondin ${ }^{46}$ have all been implicated in the recognition process. However, with respect to the signal presented on the apoptotic cell surface, PS is one central, universal component regardless of cell type ${ }^{5-8}$ or inducing stimulus ${ }^{4}$ (plus data herein), clearly identifying this event as part of the common execution pathway. The mechanisms which bring PS to the outer leaflet of the plasma membrane have the potential to be not only necessary, but also sufficient to trigger recognition. As shown here, the appearance of PS on the surface of DO11.10 cells, whether naturally as part of the apoptotic program or artificially by elevation of cytosolic $\mathrm{Ca}^{2+}$, correlates temporally with development of recognition by macrophages. These results suggest that other components of the recognition signal are present on the surface of nonapoptotic cells, but are ignored by the receptors on phagocytic cells until they are joined by PS from the cell interior. While the nature and assembly of complex PS recognition signals will be an important subject of further investigations, the centrality of PS appearance implies that understanding the regulation of PS redistribution is the key to understanding the timely appearance of a recognition signal.

Proteolytic enzymes, and caspases in particular, are essential effectors of apoptosis. In mammalian cells, however, caspases participate at multiple points in the apoptotic process, and it is not always obvious whether any particular point is part of the idiosyncratic pathway upstream of the decision to die, or part of the common execution pathway following the decision. The finding that zVAD blocks PS redistribution in DO11.10 hybridoma cells 
induced by anti-CD3 implies that there is a caspase step upstream of PS exposure in this case. ${ }^{47,48}$ This conclusion is consistent with the fact that the ZVAD-sensitive caspase8 is part of the Fas/FasL signaling pathway deployed by T lymphocyte hybridomas activated via the $\mathrm{T}$ cell receptor. ${ }^{37}$ The loss of this sensitivity to ZVAD in the same cells under the same conditions when apoptotic death is induced by glucocorticoid therefore implies that this particular caspasesensitive step is not part of the common pathway induced by both stimuli. Even so, late caspase-dependent steps, such as caspase-3 cleavage of PARP do occur during thymocyte apoptosis triggered by glucocorticoid ${ }^{49}$ in keeping with the multiple roles played by caspases in apoptosis.

The failure of $z V A D$ to block $P S$ redistribution in glucocorticoid-induced D011.10 cells argues that the translocase and scramblase are unlikely to be direct targets of the zVAD-sensitive caspases activated by antiCD3 treatment. However, caspases are not uniformly zVAD-sensitive ${ }^{50}$ and are not the only proteases proposed as participants in apoptosis. ${ }^{51,52}$ Thus neither sensitivity to zVAD nor the lack thereof are conclusive tests of whether the scramblase and translocase are themselves protease targets. That the inactivation of the translocase and activation of the scramblase are both reversible provides a stronger argument that some nonproteolytic regulatory mechanism must intervene between the redistribution of PS and the protease-dependent steps of the apoptotic pathway in these cells.

The nature of the implied nonproteolytic regulatory mechanism remains unspecified. The requirement for external $\mathrm{Ca}^{2+}$ to effect PS redistribution suggests that $\mathrm{Ca}^{2+}$ influx across the plasma membrane is essential. However, recent evidence that cytosolic $\mathrm{Ca}^{2+}$ chelators do not have the same inhibitory effects as externally applied EGTA suggests that $\mathrm{Ca}^{2+}$ acts at the cell surface. ${ }^{39}$ Notably, CTL-induced apoptosis of target cells, which occurs very rapidly, also requires external $\mathrm{Ca}^{2+} .{ }^{53}$ Understanding the role of $\mathrm{Ca}^{2+}$ in these processes may be an important step to understanding the regulation of PS redistribution which leads to cell removal.

\section{Materials and Methods}

\section{Animals}

Male CBA/J mice, 4-6 weeks of age, were maintained on food and water ad libitum in accordance with the guidelines of the Institutional Animal Care and Use Committee.

\section{Cell culture}

D011.10 cells were maintained in Eagle's Medium with glutamine at $8 \% \mathrm{CO}_{2}$ or in Dulbecco's Minimal Essential Medium (DMEM) containing glutamine and sodium pyruvate (GIBCO BRL, Gaithersburg, MD, USA) at $5 \% \mathrm{CO}_{2}$. In both cases, the medium was supplemented with $10 \%$ fetal bovine serum and cells were grown at $37^{\circ} \mathrm{C}$.

\section{Initiation of apoptosis}

Activation-induced apoptosis was initiated by transferring D011.10 cultures in log phase growth $\left(\sim 10^{6}\right.$ cells $\left./ \mathrm{ml}\right)$ to flasks with immobilized anti-CD3 monoclonal antibody (1452C11; hamster anti-mouse; Boehringer Mannheim Corp., Indianapolis, IN, USA). Glucocorticoidand phorbol ester-induced apoptosis was initiated by direct addition of dexamethasone (Sigma Chemical Co., St. Louis, MO, USA) to the culture flask to $5 \mu \mathrm{M}$ or PMA (Sigma) to $10 \mathrm{nM}$ and A23187 (Sigma) to $0.1 \mu \mathrm{g} / \mathrm{ml}$, respectively, when cells were in log phase at a density of $\sim 10^{6} / \mathrm{ml}$.

\section{Caspase inhibition}

D011.10 cells were preincubated at $37^{\circ} \mathrm{C}$ for $30 \mathrm{~min}$ with $10 \mu \mathrm{M}$ carbobenzoxy-valyl-alanyl-aspartyl-fluoromethylketone (zVAD-fmk) (Enzyme Systems Products, Dublin, CA, USA) before induction of apoptosis. Following induction, cultures were replenished with $10 \mu \mathrm{M}$ zVAD-fmk every $3 \mathrm{~h}$ until the end of the experiment.

\section{Phagocytosis assays}

Inflammatory peritoneal macrophages were prepared and plated onto coverslips as previously described. ${ }^{6}$ Untreated and treated D011.10 cells $\left(10^{6}\right)$ in $150 \mu \mathrm{L}$ of DMEM were overlayed onto triplet coverslips incubated at $37^{\circ} \mathrm{C}$ in $5 \% \mathrm{CO}_{2}$. At various times, coverslips were washed three times with ice-cold phosphate-buffered saline (PBS; $7.4 \mathrm{mM} \mathrm{Na}_{2} \mathrm{HPO}_{4}, 2.6 \mathrm{mM} \mathrm{NaH} \mathrm{PO}_{4}, 137 \mathrm{mM} \mathrm{NaCl}, 10 \mathrm{mM} \mathrm{KCl}$ ), fixed with $1.8 \%$ formaldehyde, stained with Diff-Quik (Baxter) and phagocytosed cells enumerated by microscopy as previously described, ${ }^{6}$ selecting random fields and counting 300 macrophages per coverslip.

\section{PS vesicles}

A film of brain PS (Avanti Polar Lipids, Inc.) was dried under a stream of nitrogen, followed by $4 \mathrm{~h}$ under vacuum, then hydrated in PBS to $150 \mu \mathrm{M}$ lipid and sonicated in a bath-type sonicator. ${ }^{31}$ Fifty $\mu \mathrm{L}$ $(7.5 \mathrm{nmol})$ of these vesicles was added to $10^{6}$ D011.10 cells in $100 \mu \mathrm{L}$ of DMEM, and the mixture overlayed onto macrophages.

\section{Flow cytometric analysis of lipid movements and cell death}

Aminophospholipid translocase activity, determined by the internalization of fluorescent 12-[(7-nitro-2-1,3-benzoxadiazol-4-yl)amino] dodecanoyl (NBD)-PS, and scramblase activity, determined by the internalization of NBD-phosphatidylcholine (PC), was monitored in normal and apoptotic D011.10 cells as described previously. ${ }^{13}$ Annexin V-FITC (Nexins Research B.V., Maastricht, The Netherlands) labeling was performed on $1 \mathrm{ml}$ aliquots from normal or apoptotic D011.10 cultures according to the Apoptest ${ }^{\mathrm{TM}}{ }_{-}$-FITC kit (product \#A-600) protocol sheet and cells analyzed within $10 \mathrm{~min}$. Cells which had lysed were defined as those which had lost the ability to exclude membrane-impermeant dyes, and were determined by adding to $1 \mathrm{ml}$ cell samples the membrane impermeable dye YO-PRO3 iodide (Molecular Probes Inc., Eugene, OR, USA) to $0.5 \mu \mathrm{M}$ within $1 \mathrm{~min}$ before cytometric analysis. The membrane permeable DNA chromophore acridine orange (Sigma) was used at $5 \mu \mathrm{M}$ directly on $1 \mathrm{ml}$ aliquots of normal or apoptotic cells that were analyzed within $10 \mathrm{~min}$ for chromatin degradation. All samples were analyzed on an Epics-Profile II flow cytometer (Coulter Electronics, Hialeah, FL, USA) tuned to $488 \mathrm{~nm}$. YO-PRO-3 iodide emissions were measured through 
a 635-nm bandpass filter; NBD-phospholipid fluorescence emissions, FITC annexin $\mathrm{V}$ fluorescence and acridine orange staining were detected using a 525-nm bandpass filter. Epics II workstation software was used for statistical analysis of 5000 cells from each sample. All experiments presented are representative of at least three separate experiments.

\section{Acknowledgements}

This work was supported by National Science Foundation Grant MCB9319104 and by a grant from the American Heart Association, Pennsylvania Affiliate.

\section{References}

1. CohenJJ(1993) Overview: Mechanisms of apoptosis. Immunol. Today 14:126130

2. Fadok VA, Voelker DR, Campbell PA, Cohen JJ, Bratton DL and Henson PM (1992) Exposure of phosphatidylserine on the surface of apoptotic lymphocytes triggers specific recognition and removal by macrophages. J. Immunol. 148: 2207-2216

3. Savill JS, Fadok VA, Henson PM and Haslett C (1993) Phagocyte recognition of cells undergoing apoptosis. Immunol. Today 14: 131-136

4. Martin SJ, Reutelingsperger CPM, Mcgahon AJ, Rader JA, van Schie RCAA, LaFace DM and Green DR (1995a) Early redistribution of plasma membrane phosphatidylserine is a general feature of apoptosis regardless of the initiating stimulus: Inhibition by overexpression of BCL-2 and Abl. J. Exp. Med. 182: $1545-1556$

5. Bennett MR, Gibson DF, Schwartz SM and Tait JF (1995) Binding and phagocytosis of apoptotic vascular smooth muscle cells is mediated in part by exposure of phosphatidylserine. Circ. Res. 77: 1136-1142

6. Pradhan D, Krahling S, Williamson P and Schlegel RA (1997) Multiple systems for recognition of apoptotic lymphocytes by macrophages. Mol. Biol. Cell 8: $767-$ 778

7. Shiratsuchi A, Umeda M, Ohba Y and Nakanishi Y (1997) Recognition of phosphatidylserine on the surface of apoptotic spermatogenic cells and subsequent phagocytosis by sertoli cells of the rat. J. Biol. Chem. 272: $2354-$ 2358

8. Van den Eijnde SM, Boshart L, Reutelingsperger CPM, De Zeeuw Cl and VrmeijKeers C (1997) Phosphatidylserine plasma membrane asymmetry in vivo: a pancellular phenomenon which alters during apoptosis. Cell Death Differ. 4: 311-316

9. Williamson P and Schlegel RA (1994) Back and forth: the regulation and function of transbilayer phospholipid movement in eukaryotic cells (Review). Mol. Memb. Biol. 11: 199-216

10. Tang X, Schlegel RA, Halleck $M$ and Williamson $P$ (1996) A subfamily of P-type ATPases with aminophospholipid transporting activity. Science 272: 14951497

11. Seigneuret M and Devaux PF (1984) ATP-dependent asymmetric distribution of spin-labeled phospholipids in the erythrocyte membrane: relation to shape changes. Proc. Natl. Acad. Sci. USA 81: 3751-3755

12. Zachowski A, Herrmann A, Paraf A and Devaux PF (1987) Phospholipid outsideinside translocation in lymphocyte plasma membranes is a protein-mediated phenomenon. Biochim. Biophys. Acta 897: 197-200

13. Verhoven B, Schlegel RA and Williamson P (1992) Rapid loss and restoration of lipid asymmetry by different pathways in resealed erythrocyte ghosts. Biochim. Biophys. Acta 1104: 15-23

14. Williamson P, Kulick A, Zachowski A, Schlegel RA and Devaux PF (1992) Ca ${ }^{2+}$ induces transbilayer redistribution of all major phospholipids in human erythrocytes. Biochemistry 31: $6355-6360$

15. Smeets EF, Comfurius P, Bevers EM and Zwaal RFA (1994) Calcium-induced transbilayer scrambling of fluorescent phospholipid analogs in platelets and erythrocytes. Biochim. Biophys. Acta 1195: 281-286

16. Williamson $P$, Bevers EM, Smeets EF, Comfurius $P$, SchlegelRA and Zwaal RFA (1995) Continuous analysis of the mechanism of activated transbilayer lipid movement in platelets. Biochemistry 34: 10448-10455
17. Verhoven B, Schlegel RA and Williamson $P$ (1995) Mechanisms of phosphatidylserine exposure, a phagocyte recognition signal, on apoptotic $\mathrm{T}$ lymphocytes. J. Exp. Med. 182: 1597-1601

18. Schlegel RA, Callahan M, Krahling S and Williamson P (1996) Mechanisms for recognition and phagocytosis of apoptotic lymphocytes by macrophages. In Mechanisms of Lymphocyte Activation and Immune Regulation VI. Cell Cycle and Programmed Cell Death in the Immune System. Gupta S and Cohen JJ, (eds). Plenum: New York p 21

19. Weil M, Jacobson MD, Coles HS, Davies TJ, Gardner RL, Raff KD and Raff MC (1996) Constitutive expression of the machinery for programmed cell death. J. Cell Biol. 133: 1053-1059

20. Henkart PA (1996) ICE family proteases: mediators of all apoptotic death. Immunity 4: 195-201

21. Yuan J, Shaham S, Ledoux S, Ellis HM and Horvitz HR(1993) The C. eleganscell death gene ced-3 encodes a protein similar to mammalian interleukin-1 $\beta$ converting enzyme. Cell 75: 641-652

22. Schlegel J, Peters I, Orrenius S, Miller DK, Thornberry NA, Yamin T-T and Nicholson DW (1995)CPP32/Apopain is a key interleukin $1 \beta$ converting enzymelike protease involved in Fas-mediated apoptosis. J. Biol. Chem. 271: 18411844

23. Los M, Van de Craen M, Penning LC, Schenk H, Westendorp M, Baeuerle PA, Droge W, Krammer PH, Fiers W and Schulze-Ostoff K (1995) Requirement of an ICE/CED-3 protease for Fas/APO-1-mediated apoptosis. Nature 375: 81-83

24. Enari M, Talanian RV, Wong WW and Nagata S (1996) Sequential activation of ICE-like and CPP32-like proteases during Fas-mediated apoptosis. Nature 380: $723-726$

25. Miura M, Zhu H, Rotello H, Hartwieg EA and Juan J (1993) Induction of apoptosis in fibroblastts by IL-1 $\beta$-converting enzyme, a mammalian homolog of the $C$. elegans death gene ced-3. Cell 75: 653-660

26. Milligan CE, Prevette D, Yaginuma H, Homma S, Cardwell C, Fritz LC, Tomaselli KJ, Oppenheim RW and Schwartz LM (1995) Peptide inhibitors of the ICE protease family arrest programmed cell death of motoneurons in vivo and in vitro. Neuron 15: 385-393

27. Alnemri ES, Livingston DJ, Nicholson DW, Salvesen G, Thornberry NA, Wong WW and Yuan J (1996) Human ICE/CED-3 protease nomenclature. Cell 87: 171

28. Tewari M, Quan LT, O'Rourke K, Desnoyers S, Zeng Z, Beidler DR, Poirier GG, Salvesen GS and Dixit VM (1995) Yama/CPP32 $\beta$, a mammalian homolog of CED-3, is a CrmA-inhibitable protease that cleaves the death substrate poly(ADP-ribose) polymerase. Cell 81: 801-809

29. Xue D, Shaham S and Horvitz HR(1996) The Caenorhabditis elegans cell-death protein CED-3 is a cysteine protease with substrate specificities similar to those of the human CPP32 protease. Genes Dev. 10: 1073-1083

30. Talanian RV, Christopher Q, Simone T, Hackett MC, Mankovich JA, Banach D, Ghayur T, Brady KD and Wong WW (1997) Substrate specificities of caspase family proteases. J. Biol. Chem. 272: 9677-9682

31. Gagliardini V, Fernandez P-A, Lee RKK, Drexler HCA, Rotello RJ, Fishman MC and Yuan $Y$ (1994) Prevention of vertebrate neuronal death by the $\mathrm{crmA}$ gene. Science 263: 826-828

32. Tewari M and Dixit VM (1995b) Fas- and tumor necrosis factor-induced apoptosis is inhibited by the poxvirus $\mathrm{crmA}$ gene product. J. Biol. Chem. 270: $3255-3260$

33. Thornberry NA, Bull HG, Calaycay JR, Chapman KT, Howard AD, Kostura MJ, Miller DK, Molineaux SM, Weidner JR, Aunins J et al (1992) A novel heterodimeric cysteine protease is required for interleukin- $1 \beta$ processing in monocytes. Nature 356: 768-774

34. Schlegel RA, Stevens M, Lumley-Sapanski K and Williamson P (1993) Altered lipid packing identifies apoptotic thymocytes. Immunol. Lett. 36: 283-288

35. Nakamura M, Yagi H, Kayaba S, Ishii T, Ohtsu S, Gotoh T and Itoh T (1995) Most thymocytes die in the absence of DNA fragmentation. Arch. Histol. Cytol. 58: $249-256$

36. Nakamura M, Yagi H, Kayaba S, Ishii T, Gotoh T, Ohtsu S and Itoh T (1996) Death of germinal center B cells without DNA fragmentation. Eur. J. Immunol. 26: $1211-1216$

37. Brunner T, Mogil RJ, LaFace D, Yoo NJ, Mahboubi A, Echeverri F, Martin SJ, Force WR, Lynch DH, Ware CF and Green DR (1995) Cell-autonomous Fas (CD95)/Fas-ligand interaction mediates activation-induced apoptosis in T-cell hybridomas. Nature 373: 441-444

38. Mercep M, Noguchi PD and Ashwell JD (1989) The cell cycle block and lysis of an activated $\mathrm{T}$ cell hybridoma are distinct processes with different $\mathrm{Ca}^{2+}$ requirements and sensitivity to cyclosporine A. J. Immunol. 142: 4085-4092 
39. Hampton MB, Vanags DM, PornAres MI and Orrenius S (1996) Involvement of extracellular calcium in phosphatidylserine exposure during apoptosis. FEBS Lett. 399: 277-282

40. Martin SJ and Green DR (1995b) Protease activation during apoptosis: death by a thousand cuts? Cell 82: 349-352

41. Horvitz HR, Shaham S and Hengartner MO (1994) The genetics of programmed cell death in the nematode Caenorhabditis elegans. Cold Spring Harb. Symp. Quant. Biol. 59: 377-385

42. Fadok VA, Savill JS, Haslett C, Bratton DL, Doherty DE, Campbell PA and Henson PM (1992) Different populations of macrophages use either the vitronectin receptor or the phosphatidylserine receptor to recognize and remove apoptotic cells. J. Immunol. 149: 4029-4035

43. Duvall E, Wyllie AH and Morris RG (1985) Macrophage recognition of cells undergoing programmed cell death (apoptosis). Immunology 56: 351-358

44. Flora PK and Gregory CD (1994) Recognition of apoptotic cells by human macrophages: inhibition by a monocyte/macrophage-specific monoclonal antibody. Eur. J. Immunol. 24: 2625-2632

45. Devitt A, Raykundala C, Moffatt OD, Capra JD, Simmons DL and Gregory CD (1998) Human Cd14 mediates recognition and phagocytosis of cells undergoing apoptosis. Nature 392: 505-509

46. Savill JS, Hogg N, Ren Y and Haslett C (1992) Thrombospondin cooperates with CD36 and the vitronectin receptor in macrophage recognition of neutrophils undergoing apoptosis. J. Clin. Invest. 90: 1513-1522
47. Martin SJ, Finucane DM, Amarante-Mendes GP, O'Brien GA and Green DR (1996) Phosphatidylserine externalization during CD95-induced apoptosis of cells and cytoplasts requires ICE/CED-3 protease activity. J. Biol. Chem. 271: 28753-28756

48. Naito M, Nagashima K, Mashima T and Tsuruo T (1997) Phosphatidylserine externalization is a downstream event of ICE family protease activation during apoptosis. Blood 89: 2060-2066

49. Fearnhead HO, Dinsdale D and Cohen GM (1995) An interleukin-1 betaconverting enzyme-like protease is a common mediator of apoptosis in thymocytes. FEBS Lett. 375: 283-288

50. Sarin A, Wu ML and Henkart PA (1996) Different interleukin-1 beta converting enzyme (ICE) family protease requirements for the apoptotic death of $\mathrm{T}$ lymphocytes triggered by diverse stimuli. J. Exp. Med. 184: 2445-2450

51. Squier MK, Miller AC, Malkinson AM and Cohen JJ (1994) Calpain activation in apoptosis. J. Cell. Physiol. 159: 229-237

52. Squier MK and Cohen JJ (1997) Calpain, an upstream regulator of thymocyte apoptosis. J. Immunol. 158: 3690-3697

53. Kraut RP, Bose R, Cragoe EJ and Greenberg $\mathrm{AH}$ (1992) The $\mathrm{Na}^{+} / \mathrm{Ca}^{2+}$ exchanger regulates cytolysin/perforin-induced increases in intracellular $\mathrm{Ca}^{2+}$ and susceptibility to cytolisis. J. Immunol. 148: 2489-2496 